\title{
Comparative Study on the Spermatheca of Some Orthopteran Insects
}

\author{
Anuradha A. Sathe and P. V. Joshi \\ Department of Zoology, University of Poona, Pune 411007 , India
}

Accepted June 26, 1987

In the female insects, after mating spermatozoa are stored in specialised sperm storage organ, the spermatheca. This is ectodermal in origin. The stored sperms may retain their fertilization capacity for months or even years. Various workers have described morphology of the spermathecae of some orthopteran insects; however very few have reported its histology. Morphology as well histology plays an important role in categorizing the spermatheca, hence the present work was undertaken.

The published accounts on the spermatheca of orthopteroid insects include those of Qadri (1940), Slifer (1939, 1940a, 1940b, 1940c, 1943a, 1943b), Gupta (1948), Voy (1949), Katiyar (1956), Kugler et al. (1956), Dirsh (1957), Gupta and Smith (1969), Kevan et al. (1969), Wagan (1980), Ahmed and Gillott (1982), Kharibam et al. (1982) and Pal and Ghosh (1982).

The spermathecae are either partialc glandular in their construction or they are associated with tubular spermathecal glands, the function of which is to provide an exogenous nutrient source for the spermatozoa.

As reported by earlier workers, in the orthopteroid insects the spermathecal gland is lacking. The spermathecal epithelium is made up of two distinct layers of cells, outer layer of secretory and inner of chitogenous cells (Gupta and Smith 1969, Ahmed and Gillott 1982, Pal and Ghosh 1982).

\section{Materials and methods}

Females specimens of Gryllus domesticus F. and Liogryllus bimaculatus de G. (F-Gryllidae), Gryllotalpa africana Pal. B. (F-Gryllotalpidae), Acrida exaltata Walk., Hieroglyphus banian F., Teratodus monticollis Gray and Gastrimargus transversus Thunb. (F-Acrididae) were collected from local fields of Pune (India). Spermathecae were dissected in $0.6 \%$ saline for morphological observations and were sketched by camera lucida. For histology, formal saline fixed spermathecae were dehydrated in graded ethanol, cleared in xylene, embedded in paraffin, sectioned at $8 \mu \mathrm{m}$ and stained with Delafield's hematoxylin and $1 \%$ alcoholic eosin.

\section{Observations and results}

Morphologically the spermatheca can be categorised into four groups:

1. Sac like

2. Oval pouch like

3. Spermatheca with apical appendage

4. In the form of sperm storing tubules

1) Sac like spermatheca

This type is present in G. domesticus and L. bimaculatus (Figs. 1, 2). The spermatheca (SP) is situated on the dorsal side of the common oviduct with spirally coiled spermathecal 
duct (SD) which extends posteriorly and opens in the bursa copulatrix (BR).

The spermathecal epithelium (Fig. 8, EP) is supported by a basement membrane and con-

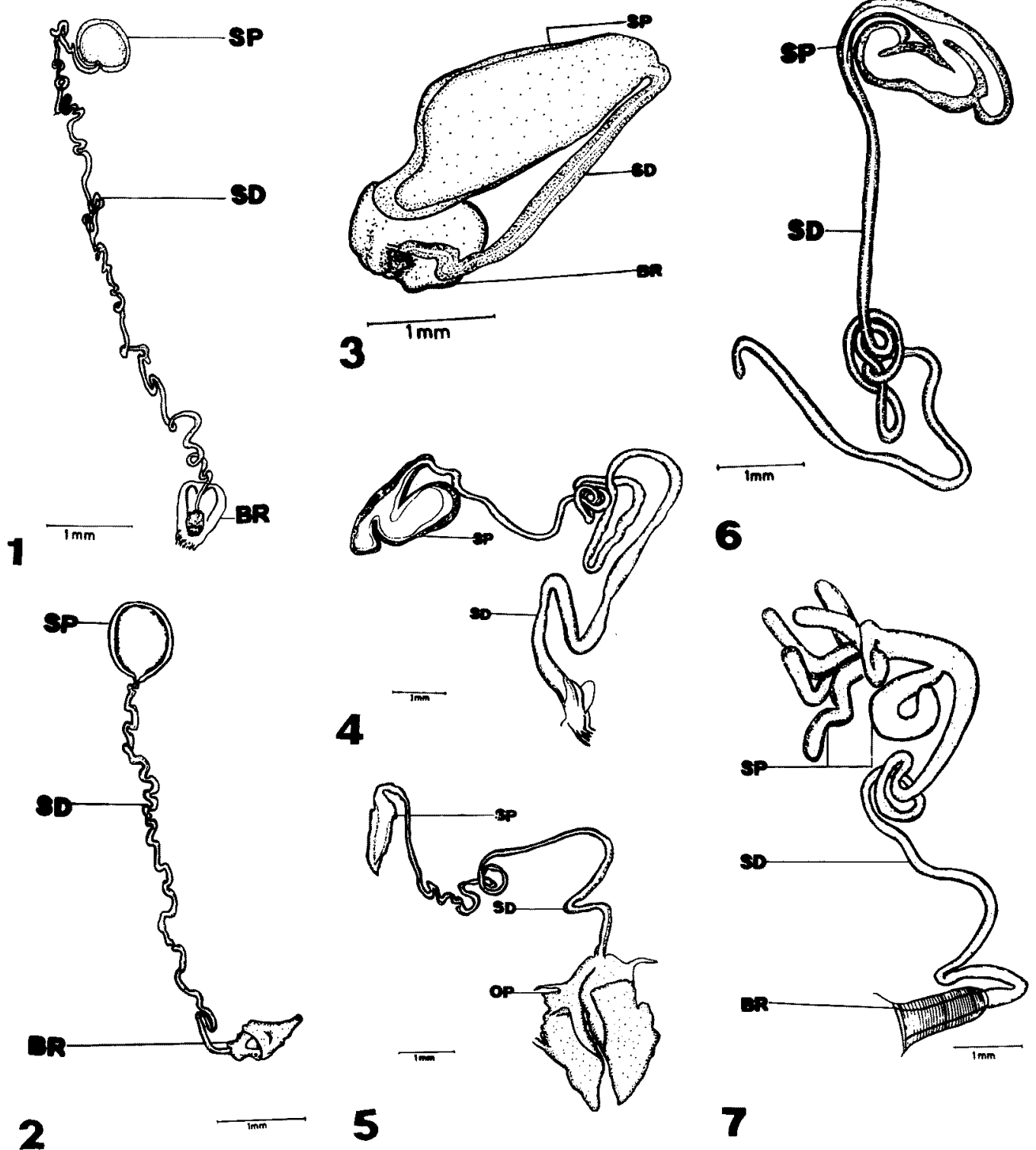

Abbreviations, Figs. 1-14. BM: basement membrane. BR: bursa copulatrix. EP: epithelium. IN: chitinous intima. MC: muscle coat. $\mathrm{N}$ : nucleus. $\mathrm{N}_{1}$ : nucleus of outer layer cell. $\mathbf{N}_{2}$ : nucleus of inner layer cell. OP: ovipositor. SD: spermathecal duct. SP: spermatheca.

Figs. 1-7. 1, whole mount of spermatheca of $G$. domesticus; spermatheca (SP), spermathecal duct (SD) and bursa copulatrix (BR). 2, whole mount of spermatheca of L. bimaculatus; spermatheca (SP), spermathecal duct (SD) and bursa copulatrix (BR). 3, whole mount of spermatheca of $G$. africana; spermatheca (SP), spermathecal duct (SD) and bursa copulatrix (BR). 4, whole mount of spermatheca of $A$. exaltata; spermatheca (SP), spermathecal duct (SD). 5, whole mount of spermatheca of G. transversus; spermatheca (SP), spermathecal duct (SD) and ovipositor (OP). 6, whole mount of spermatheca of $H$. banian; spermatheca (SP) and spermathecal duct (SD). 7, whole mount of spermatheca of $T$. monticollis; spermatheca (SP), spermathecal duct (SD) and bursa copulatrix (BR). 
sists of a single layer of cuboidal cells with oval nuclei $(N)$. It is surrounded by a very thin muscle coat and is internally lined by a thin chitinous intima (IN).

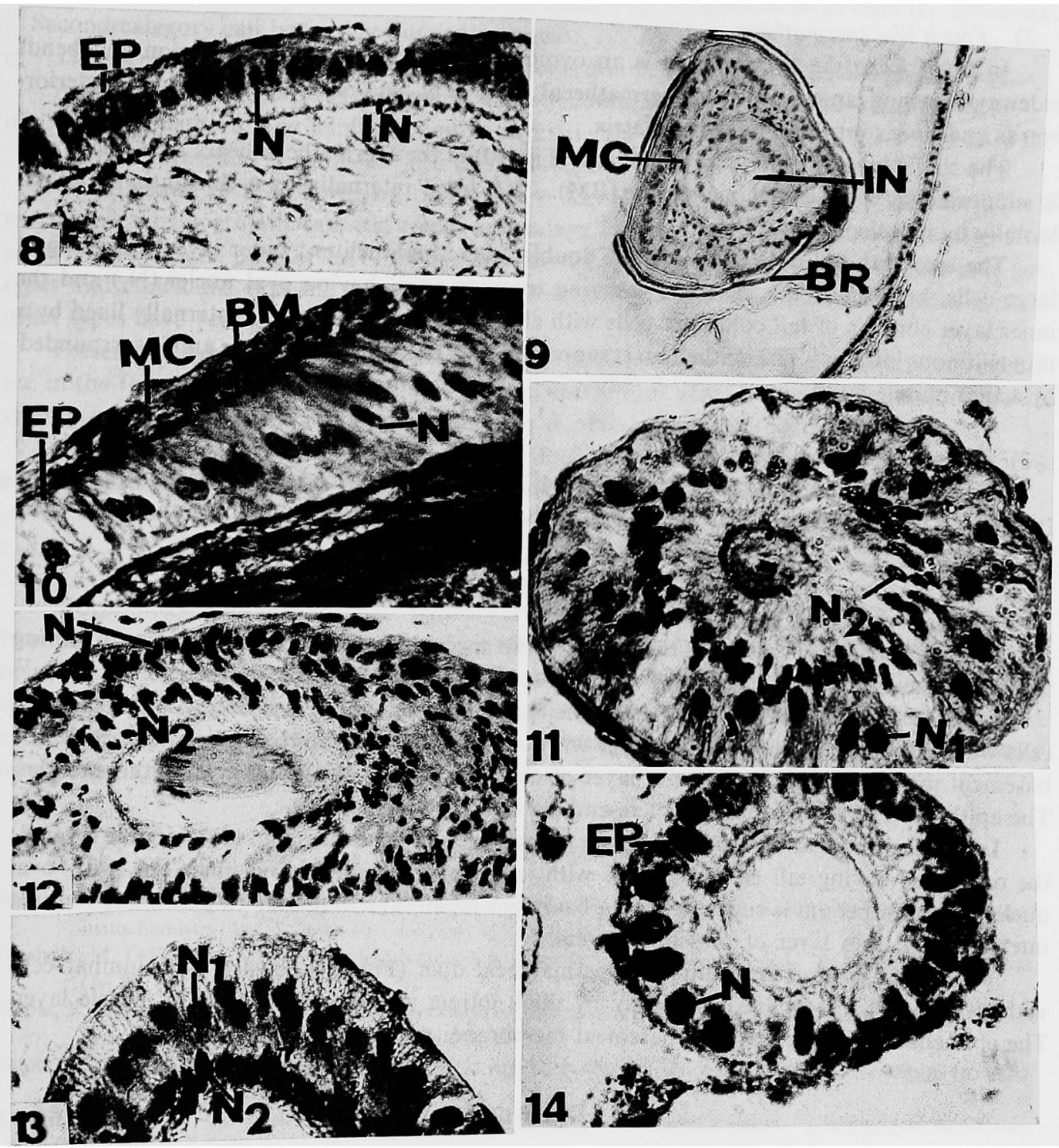

Figs. 8-14. 8, transverse section of spermatheca of $G$. domesticus showing single layered epithelium; epithelium (EP), nucleus $(\mathrm{N})$ and intima (IN). $\times 1,500 . \quad 9$, transverse section of spermathecal duct of G.domesticus passing through wall of the bursa copulatrix (BR): note the single layered epithelium; thickened intima (IN) and muscle coat (MC). $\times 500.10$, transverse section of spermatheca of $G$. africana showing single layered epithelium; epithelium (EP), nucleus (N), basement membrane (BM) and muscle coat (MC). $\times 1,400.11$, transverse section of the spermathecal duct of $G$. africana showing double layered epithelium; nucleus of outer layer cell $\left(\mathrm{N}_{1}\right)$ and nucleus of inner layer cell $\left(\mathrm{N}_{2}\right) . \quad \times 1,000 . \quad 12$, transverse section of the sperm storing tubule of $H$. banian showing double layered epithelium; nucleus of outer layer cell $\left(\mathrm{N}_{1}\right)$ and nucleus of inner layer cell $\left(\mathrm{N}_{2}\right)$. $\times 1,200$. Structure of the spermathecal duct is identical. 13, transverse section of spermatheca of G. transversus: note the double layered epithelium; nucleus of outer layer cell $\left(\mathrm{N}_{1}\right)$ and nucleus of inner layer cell $\left(\mathrm{N}_{2}\right) . \times 1,250 . \quad 14$, transverse section of the spermathecal duct of G. transversus showing single layered epithelium (EP) and nucleus $(\mathrm{N}) . \quad \times 1,350$. 
The epithelium of spermathecal duct (Fig. 9) resembles that of spermatheca. However, intima and muscle layer is comparatively more thicker in spermathecal duct.

\section{2) Pouch like spermatheca}

In $G$. africana the spermatheca is an ovoid pouch, broader at middle region and bends sideways making an angle with spermathecal duct (Fig. 3). The duct extends posteriorwards and opens into the bursa copulatrix.

The single layered columnar epithelium (Fig. 10) of the spermatheca bears oval nuclei and is supported by a basement membrane (BM). It is lined internally by a thin intima and externally by muscle layer (MC).

The spermathecal duct (Fig. 11) has double layered epithelium; outer layer consisting of large cells, broader at the base and tapering towards apex, having oval nuclei $\left(\mathrm{N}_{1}\right)$ and the inner layer consists of tall columnar cells with elliptical nuclei $\left(\mathrm{N}_{2}\right)$. It is internally lined by a thin chitinous intima. The epithelium is supported by a basement membrane and is surrounded by a thin muscle layer.

\section{3) Spermatheca with apical appendage}

In $A$. exaltata and $G$. transversus (Figs. 4,5 ) the spermatheca is with apical appendage. It opens in between the bases of the valves of the ovipositor (OP) by a highly convoluted spermathecal duct.

\section{4) Sperm storing tubules}

In $H$. banian and $T$. monticollis (Figs. 6,7 ) the spermatheca is in the form of sperm storing tubules, the number of tubules being two and seven respectively.

In A. exaltata and H. banian (Fig. 12) the epithelium is double layered: the outer layer of cells with elliptical nuclei and inner layer with oval nuclei. The epithelium is supported by a basement membrane and bears inner layer of chitinous intima and outer layer of thin muscles. The epithelium of spermathecal duct resembles with the spermatheca.

In G. transversus and T. monticollis the spermathecal epithelium (Fig. 13) is double layered: the outer one having tall columnar cells with large spherical nuclei and inner one with oval nuclei. The epithelium is supported by a basement membrane and bear thin chitinous intima internally and thin layer of muscles externally.

The single layered epithelium of spermathecal duct (Fig. 14) consists of columnar cells with oval nuclei. It is lined internally by thick intima and externally by thin muscle layer. The epithelium is supported by a basement membrane.

\section{Discussion}

In higher insect orders like Coleoptera and Hymenoptera the spermathecae are associated with spermathecal gland. In present studies, the spermathecal gland was not observed.

From histological point of view the spermathecal epithelium can be categorized into two:

1. Single layered epithelium made up of chitogenous cells.

2. Double layered epithelium consisting of outer layer of secretory cells and inner of chitogenous cells.

Double layered epithelium is reported by Gupta and Smith (1969) in Periplaneta americana, Ahmed and Gillott (1982) in Melanoplus sanguinipes and Pal and Ghosh (1982) in Gesonula punctifrons.

First category can be further divided into two:

a) An epithelium is single layered and consists of chitogenous cells (G. domesticus and $L$. 
bimaculatus). In this case, how the sperms in the spermatheca are kept viable is unknown.

b) Spermathecal epithelium is single layered but surprisingly, the duct is double layered. In this case the secretory function seems to be taken over by spermathecal duct (G. africana). Second category can be further divided into two:

c) The spermatheca as well as spermathecal duct is double layered (A. exaltata and H. banian). Ahmed and Gillott (1982) observed similar condition in Melanoplus sanguinipes.

d) The spermathecal epithelium is double layered, but the epithelium of spermathecal duct is single layered ( $T$. monticollis and $G$. transversus).

On the basis of morphological observations Kevan et al., (1969) generalised that paired spermatheca or spermatheca with apical appendage is more primitive to Orthoptera as well as in related orders, but Dirsh (1957) has categorized the spermathecae of Acridoidea into five types and concluded that the simple pear shaped spermatheca is primitive and from this all other types have been evolved.

Present morphological and histological observations reveal that the spermathecae which are in the form of single sac have single layered epithelium while, those in the form of sperm storing tubules or with apical appendage have double layered epithelium.

It is obvious that a spermatheca having a double layered epithelium (Acrididae) is more evolved than the spermatheca having a single layered epithelium (Gryllidae).

\section{Summary}

Morphology and histology of spermatheca of seven orthopteran insects is compared. None of the spermathecae are associated with spermathecal accessory gland. Observations reveal that the spermatheca, which is in the form of a sac, has single layered epithelium while spermatheca with apical appendage, or in the form of sperm storing tubules, has double-layered epithelium. The double-layered epithelium is probably more evolved where the outer layer is secretory and the inner is chitogenous in nature.

\section{Literature cited}

Ahmed, Ijaz and Gillott, C. 1982. The spermatheca of Melanoplus sanguinipes: 1. Morphology, histology and histochemistry. Int. J. Invertebr. Reprod. 4(5): 281-296.

Dirsh, V. M. 1957. The spermatheca as a taxonomic character in Acridoidea. Proc. R. Entomol. Soc. Lond. (A) 32: 107-114.

Gupta, B. L. and Smith, D. S. 1969. Fine structural organization of the spermatheca in the cockroach, Periplaneta americana. Tissue and Cell 1(2): 295-324.

Gupta, P. D. 1948 . On the structure, development and homology of the female reproductive organs in orthopteroid insects. Indian J. Ent. 10: 75-123.

Katiyar, R. N. 1956. On variation in the spermathecae of some Indian grasshoppers. (Orthoptera: Acrididae). J. Zool. Soc. India 8: $35-42$.

Kevan, D. K. McE., Akbar, S. S. and Chang, Yu Cheng (1969). The concealed copulatory structures of the Pyrgomorphidae. EOS. 44: 165-216.

Kharibam, M., Shafee, S. A. and Usmani, M. K. 1982. Taxonomic significance of spermatheca in some Indian grasshoppers. (Orthoptera: Acrididae). J. Bombay Nat. Hist. Soc., 79(2): 331-335.

Kugler, O. E., Frankenstein, P. W. and Rafferty, J. R. K. A. 1956. Histochemical localization of alkaline phosphatase, glycogen and nucleic acids in the female reproductive organs of the cockroach, Periplaneta americana. J. Morphol. 98: 235-261.

Pal, S. G. and Ghosh, D. 1982. Electron microscopic study of the spermatheca of Gesonula punctifrons (Acrididae: Orthoptera). Proc. Indian Acad. Sci. Anim. Sci. 9(2): 99-112.

Qadri, M. A. H. 1940. On the development of the genitalia and their ducts of orthopteroid insects. Trans. R. Ento. Soc. Lond. 90(6): 121-175.

Slifer, E. H. 1939. The internal genitalia of female Acrididae, Oedipodinae and Paulininae (Orthoptera: Acrididae). J. Morphol. 65: 435-469. 
- 1940a. The internal genitalia of female Thrinchinae, Batrachotetrigidae, Pamphaginae and Pyrgomorphinae (Orthoptera-Acrididae). Ibid, 66: 175-185.

- 1940b. The internal genitalia of female Ommexechinae and Cyrcanthacridinae (Orthoptera: Acrididae). Ibid 67: 199-239.

- 1940c. Variations in the spermatheca of two species of grasshoppers (Orthoptera-Acrididae). Ent. News 51: $1-3$.

- 1943a. The internal genitalia of some previously unstudied species of female Acrididae (Orthoptera). J. Morphol. 72: 225-237.

- 1943b. The internal genitalia of female Tetrigidae, Eumasticidae and Proscopiidae (Orthoptera). Ibid 73: 89-110.

Voy, A. 1949. Contribution à l'étude anatomique et histologique des organes accessories de l'appareil génital femelle chez quelques espèces d'Orthoptèroides. Ann. Sci. Nat. Zool. Ser. 11, 11: 269-345.

Wagan, M. S. 1980. A comparative study of female reproductive organs of Orthoptera from Sind. Pakistani J. Zool. 12(1): 17-25. 